\title{
Prevalence of human papillomavirus genotype among Moroccan women during a local screening program
}

\author{
Zaitouna Alhamany ${ }^{1,4}$, Mohammed El Mzibri ${ }^{2}$, Aïcha Kharbach ${ }^{3}$, Abderrahmane Malihy ${ }^{1}$, Redouane \\ Abouqal $^{4}$, Hassan Jaddi ${ }^{2}$, Ali Benomar ${ }^{4}$, Mohammed Attaleb ${ }^{2}$, Najat Lamalmi ${ }^{1}$ and Nadia Cherradi ${ }^{1}$ \\ ${ }^{1}$ Département d'Anatomie pathologique. Maternité Souissi, Centre Hospitalier Universitaire Ibn Sina. Rabat, \\ Morocco \\ ${ }^{2}$ Unité de Biologie et Recherches Médicales, Centre National de l'Energie, des Sciences et Techniques Nucléaires, \\ Rabat, Morocco. \\ ${ }^{3}$ Département de Gynécologie Obstétrique. Maternité Souissi, Centre Hospitalier Universitaire Ibn Sina, Rabat, \\ Morocco \\ ${ }^{4}$ Centre de Recherche Clinique, Epidémiologique et essais thérapeutiques. Faculté de Médecine et Pharmacie, \\ Rabat, Morocco.
}

\begin{abstract}
Introduction: Many studies have indicated a causal relationship between genital human papillomavirus (HPV) infections and cervical cancer. This study aimed to determine the prevalence and genotypes of six high-risk oncogenic human papillomaviruses in cervical lesions from Moroccan women with normal and abnormal cytology.

Methodology: The study included 938 women from the Children's and Mothers' Pathology Department of Ibn Sina Hospital, Rabat. Cytopathology examination was done by routine PAP smear testing. HPV DNA testing was conducted using DNA amplification by Polymerase Chain Reaction with subsequent typing by hybridization with specific probes for HPV types 16, 18, 31, 33, 35 and 45.

Results: Cytopathology testing showed that only $16.3 \%$ had an abnormal cytology, with a predominance of atypical squamous cell of undetermined significance (ASCUS) cases. The overall HPV prevalence was $15.7 \%$. According to the cytology results, HPV infection was detected in $15.8 \%$ of normal and $14.38 \%$ of abnormal cases. Specific HPV genotyping showed a predominance of HPV 16 and 18 . Double infection (HPV $16+18$ ) was found in two cases whereas multiple infections (HPV 16+18+31) were detected in only one case.

Evaluation of the relationship between HPV status and some environmental risk factors, including individual, socio-economic, and hygiene status, showed a significant association between HPV infection and oral contraceptive use.

Conclusion: Based on these data, a combination of cytology and HPV DNA testing allows for identification of patients with a high risk of developing high-grade cervical lesions and improves cervical cancer prevention.
\end{abstract}

Key words: HPV; cervical cancer; PCR; molecular hybridization; Morocco

J Infect Dev Ctries 2010; 4(11):732-739.

(Received 24 December 2009 - Accepted 13 September 2010)

Copyright $@ 2010$ Alhamany et al. This is an open-access article distributed under the Creative Commons Attribution License, which permits unrestricted use, distribution, and reproduction in any medium, provided the original work is properly cited.

\section{Introduction}

Worldwide, cervical cancer is the second most common malignancy in women with nearly half a million new cases diagnosed and 200,000 deaths each year [1]. In Morocco, published statistics showed that cervical cancer represents a serious public health problem and in the absence of a national cancer registry, data are limited to the number of cases registered in some medical centres [2]. The hospitalbased cancer registry of the National Institute of Oncology (INO), Rabat, reports more than 500 new cases annually [2].
Clinical and epidemiological studies have identified human papillomavirus (HPV) as the central risk factor for cervical cancer development [3]. HPV belong to the Papillomaviridae, and infection with specific mucosal HPV types has been shown to be associated with the development of cervical intraepithelial neoplasia lesions and cancer [4,5].

To date, more than 200 HPV genotypes have been identified [6], but the interest is focused only on genital HPV (40 genotypes) that are associated with precancerous and cancerous lesions of the cervix [7]. HPV genotypes vary in oncogenic potential and are 
associated with anatomically and histologically different diseases.

HPV types have been grouped into low-risk and high-risk types based on the frequency of association with invasive cervical cancer. Some HPV types considered low risk, such as 6 and 11, cause benign condylomas, whereas a wider number of subtypes considered as high risk have been shown to be involved in cervical carcinogenesis. Among them, HPV 16 and 18 genotypes, which are frequently found in association with cervical cancer, are considered the most oncogenic types. Other HPVs, $31,33,35,45,51,52,58$ and 59, that are also considered as carcinogenic, are less frequent in cervical carcinomas $[8,9,10]$. When HPV infection occurs, the viral DNA is present in the cell as an episomal plasmid. Persistence of infection favors viral integration in the cell genome which, together with other factors, can progress to high-grade squamous intraepithelial lesions (HSIL) and cancer $[11,12]$. Usually, there is a long latency period between the time of HPV infection and the appearance of cancer.

Currently, cervical lesion diagnosis is based only on cyto- and histopathology analyses. Cytology diagnosis, especially using the Pap smear screening test, has largely contributed to decreasing mortality by cervical cancer and has been very successful in lowering the rate of cervical cancer in countries with high coverage and good quality control. However, a number of problems with cytology have been demonstrated, including sensitivity and quality sample interpretive errors due to the subjectivity of the reading of slides, leading to a greater number of interpretive errors [12]. The low sensitivity of cytology has major medical, economic, and medicolegal implications [12]. Cuzick et al. (2006) provided a meta-analysis with a direct comparison between cytology and HPV DNA testing. In this analysis, sensitivity of cytology was substantially lower than for HPV DNA testing and varied considerably between studies; however, HPV DNA testing is less specific [12].

HPV DNA testing for cancer-associated HPV DNA is now accepted as a viable and valid option in the treatment of women with equivocal cytological findings and, in recent years, there has been an increasing interest in the use of HPV DNA testing in cervical samples from asymptomatic women without cytological abnormalities $[13,14]$.

This study was conducted to determine the prevalence of the most oncogenic HPV in the
Moroccan population and to evaluate the simultaneous screening of cervical lesions with Pap smear and HPV DNA testing to establish the contribution of HPV DNA testing to cervical cancer management in Morocco. Also, some risk factors associated with cervical cancer development were evaluated using the hospital case control database.

\section{Methodology Specimens}

A total of 938 uterine cervix samples were collected from women visiting the family planning service at the maternity department of Centre Hospitalier Universitaire (CHU) Ibn Sina, Rabat, between October 2006 and October 2007. Women who had undergone a hysterectomy or who were pregnant were excluded. For each woman, a questionnaire was completed including age, marital status, socio-economical status, parity, contraceptive practice and the presence of any gynaecological symptoms.

The characteristics of the study population are reported in Table I. The mean age of women was 42.5 with extreme ages at 17 and 80 . More than $90 \%$ lived in an urban area, most frequently in Rabat. All of them were married and had been pregnant. The majority of the participants reported one lifetime sexual partner. A history of contraceptive use was reported by about $47.9 \%$ of women, including $19.2 \%$ using an intrauterine device and $28.7 \%$ using an oral contraceptive. Two women reported family neoplasia history (breast and digestive tracts) and more than $39 \%$ of participating women had never had a Pap test for cervical lesion diagnosis.

Scraped cervical cells were collected by an experienced gynaecologist or pathologist from each woman using a cervix brush. Cell suspensions, containing ectocervical and endocervical cells, were smeared one slide for Pap testing. The remaining scraped cervical cells were transferred to sterile vials containing $5 \mathrm{ml}$ phosphate buffered saline (PBS) for HPV DNA testing.

\section{Pathology}

Cells were fixed with alcohol or with lacquer and coloured using the Papanicolaou method. Histological assessment was performed by pathologists in the anatomy pathology department at the Children's and Mothers' Pathology Department, CHU Ibn Sina, Rabat. The results of the Pap smears were classified according to the Bethesda System $2001[9,10,15,16]$. 


\section{$H P V$ detection and typing}

DNA extraction: DNA was extracted from cervical cells. Cells were lysed in the digestion buffer (Tris-HCl $10 \mathrm{mM}$ pH 8.0, EDTA $10 \mathrm{mM}, \mathrm{NaCl} 150$ $\mathrm{mM}$ and SDS 2\%) containing proteinase $\mathrm{K}$ $(0.1 \mathrm{mg} / \mathrm{ml})$ (Promega, Charbonnieres - France). DNA isolation was performed with phenol-chloroform extraction and ethanol precipitation. DNA was then resuspended in sterile distilled water, and stored at $20^{\circ} \mathrm{C}$ until use [17].

DNA amplification: All the primers and probes used in this study were purchased from Operon (Paris, France). The first aliquot of a given extract was screened with a $\beta$-globin Polymerase chain reaction (PCR) using $\mathrm{PC} 03$ and $\mathrm{GH} 20$ primers that allow the amplification of a 123 base pair (bp) fragment [18]. This first amplification was used to check the DNA quality and competence. A second aliquot was used for HPV DNA detection and typing. DNA was amplified by the polymerase chain reaction (PCR) using consensus primers: MY 09 and MY 11 that allow the amplification of 450-bp target sequences of the L1 region that is highly conserved on a broad spectrum of HPVs [19].

Amplification reaction was performed in total volume of $50 \mu \mathrm{l}$. The amplification mixture contained 50 pmol of each consensus primer, $200 \mu \mathrm{M}$ of each dNTP (dATP, dCTP, dGTP and dTTP), 0.625 units Taq DNA polymerase (Amersham, England) and $5 \mu \mathrm{l}$ of DNA sample in 1x Taq polymerase buffer. The mixture was first denatured at $94^{\circ} \mathrm{C}$ for seven minutes. Then 35 cycles of PCR were performed, in the GeneAmp PCR System 9700 (Applied Biosystems, Foster City, CA, USA), with denaturation at $94^{\circ} \mathrm{C}$ for 30 seconds, primer annealing for one minute at $56^{\circ} \mathrm{C}$ and primer extension for one minute 30 seconds at $72^{\circ} \mathrm{C}$. At the end of the last cycle, the mixture was incubated at $72^{\circ} \mathrm{C}$ for seven minutes. For every reaction, a negative control in which the DNA template was omitted from the amplification mixture and a positive control were included.

Hybridisation analysis of PCR products: Aliquots of $10 \mu \mathrm{l}$ of the PCR product were analysed by electrophoresis through $1 \%$ agarose gel. The $50 \mathrm{bp}$ ladder molecular-weight marker (Amersham, England) was included for detection of the DNA size of the amplification product.

PCR products were transferred onto positively charged nitrocellulose membranes (Hybond $\mathrm{N}+$ Amersham, England) and fixed by incubation at $80^{\circ} \mathrm{C}$ for two hours. HPV-specific probes were biotin labelled and hybridized under stringent conditions to amplicons on the membrane as described previously [17]. The probes used in this study were MY14 (CATACACCTCCAGCACCTAA), WD74 (GGATGCTGCACCGGCTGA), WD126 (CAAAAGCCCAAGGAAGATC), MY16 (CACACAAGTAACTAGTGACAG), MY115 (CTGCTGTGTCTTCTAGTGACAG) and MY70 (TAGTGGACACTACCCGCAG), which are specific to HPV 16, 18, 31, 33, 35 and 45 respectively. Membranes were then washed under normal and stringent conditions and specific hybrids were revealed using the biotin luminescence detection kit according to the manufacturer's instructions (Biolabs, England). Finally, membranes were exposed for 30 minutes on X-ray film (Hyperfilm ECL, Amersham, England).

Table 1 - Characteristics of 938 participating women in the cytology and HPV testing project

\begin{tabular}{|c|c|c|c|}
\hline \multicolumn{2}{|c|}{ Characteristics } & $\mathrm{N}$ & $\%$ \\
\hline \multicolumn{4}{|c|}{ Age $\quad$ Mean age: $42,5(17-80 ; 9,5)$} \\
\hline & $<29$ & 90 & 9.6 \\
\hline & $\geq 30$ & 848 & 90.4 \\
\hline \multicolumn{4}{|c|}{ Residence } \\
\hline & Urban & 845 & 90.1 \\
\hline & Rural & 93 & 9.9 \\
\hline \multicolumn{4}{|c|}{ Sexual partner } \\
\hline & Single & 912 & 97.2 \\
\hline & Multiple & 26 & 2.8 \\
\hline \multicolumn{4}{|c|}{ Parity } \\
\hline & Less than 3 children & 401 & 42.7 \\
\hline & Three children or more & 537 & 57.3 \\
\hline \multicolumn{4}{|c|}{ Family Income $^{\mathrm{a}}$} \\
\hline & $0-2$ minimum salaries per month & 258 & 27.5 \\
\hline & $>2$ minimum salaries per month & 680 & 72.5 \\
\hline \multicolumn{2}{|c|}{ Abortion } & 302 & 32.2 \\
\hline \multicolumn{2}{|c|}{ Contraception } & 449 & 47.9 \\
\hline & Intra-uterine device(IUD) & 180 & 19.2 \\
\hline & Oral contraceptive(OC) & 269 & 28.7 \\
\hline \multicolumn{4}{|c|}{ Previous cytology diagnosis with pap test } \\
\hline & Never & 366 & 39 \\
\hline & $\geq 1$ & 572 & 61 \\
\hline
\end{tabular}

a: The minimum salary is about $120 \$$ 
Statistical analysis: A data bank including demographic and behavioural factors was generated and analyzed using the statistical software package SPSS (SPSS, Inc., Chicago, IL, USA). Crude and adjusted odds ratio (OR) tests for trends with $95 \%$ confidence intervals $(95 \% \mathrm{CI})$ and chi-square tests were used when appropriate. The significance level for the tests (p) was set at 0.05 .

\section{Results}

The cytological results of the 938 swabs showed that $83.7 \%$ had normal cytology (785/938). Among the 153 abnormal cytology cases, 60 were classified as non-specific inflammations; 46 cases were atypical squamous cell of undetermined significance (ASCUS); and 16 cases were atypical squamous cell not excluding high-grade lesion (ASCH), whereas low-grade squamous intra-epithelial lesions (LSIL) and high-grade squamous intra-epithelial lesions (HSIL) were found respectively in 24 cases and 7 cases (Table 2). In this cohort, no cytology indicating cervical cancer was observed.

The presence of amplifiable DNA, using primers for a fragment of $\beta$-globin gene, was confirmed in all cases and all DNA samples were adequate for further analyses. Successful amplification of HPV-positive DNA preparations with MY11/MY09 primers yielded a DNA fragment of $450 \mathrm{pb}$ corresponding to the PCR products of HPV L1 gene.

Using PCR amplification combined with molecular probing, the presence of HPV DNA in $15.6 \%$ of cases $(146 / 938)$ was revealed. The distributions of viral genotypes in the $146 \mathrm{HPV}$ positive cases are reported in Table 2. Molecular typing showed single and multiple infections with a predominance of HPV 16 and 18. HPV 16 and 18, alone or in coinfections, were present in $15.75 \%$
(23/146) and $10.96 \%$ (16/146) of cases respectively, whereas the others types had a low prevalence.

In the normal group, HPV DNA was detected in $15.8 \%$ of cases (124/785). Molecular analysis showed that there was no conifection. HPV 16 and 18 , the most predominant genotypes, were present respectively in $13.71 \%(17 / 124)$ and $8.87 \%(11 / 124)$ of HPV-positive cases.

In the abnormal group, HPV DNA was found in $14.38 \%$ of cases $(22 / 153)$. Viral distribution showed the presence of HPV 16, 18, 31 and 33. Two cases were double infected with HPV 16 and 18 and only one case was infected by HPV 16, 18 and 31. No specimen harboured the other genotypes, HPV 35 and 45. Among the $146 \mathrm{HPV}$ positive cases, 97 were untyped and hence were not related to other HPV genotypes.

According to the cytological diagnosis, the viral genotype distribution showed the absence of the six high-risk HPV in the NSI group (Table 2). Moreover, stratification of abnormal cytology showed that HPV 16, alone or in combination with other HPV genotypes (18 and 31), was found mainly in advanced lesions. Interestingly, the triple infection with HPV16, 18 and 31 was found in the HSIL case. Double infection with HPV 16 and 18 were found in two cases; one was LSIL and the other corresponded to an ASCUS.

The evaluation of the relationship between HPV infection and some environmental risk factors is reported in Table 3. Statistical analysis showed that the use of oral contraceptives showed a significant association $(p=0.0206)$. The other risk factors did not show any significant association in the population study. On the other hand, among the 912 women declaring a single life sexual partner, 141 were HPV positive (15.39\%).

Table 2: Distribution of HPV genotypes in cervical swabs according to the cytological results

\begin{tabular}{|c|l|l|l|l|l|l|l|l|l|l|l|}
\hline & N & HPV+ Cases & HPV 16 & HPV 18 & HPV 16+18 & HPV 31 & HPV 33 & HPV 35 & HPV 45 & HPV16+18+31 & Unknown \\
\hline Normal & 785 & 124 & 17 & 11 & & 4 & 1 & 3 & 2 & & 86 \\
\hline Abnormal & & & & & & & & & & & \\
\hline NSI & 60 & 11 & & & & & & & & & 11 \\
\hline SCUS & 46 & 3 & & & 1 & 1 & 1 & & & & \\
\hline ASCH & 16 & 1 & & 1 & & & & & & & \\
\hline LSIL & 24 & 4 & 3 & & 1 & & & & & & \\
\hline HSIL & 7 & 3 & & 1 & & 1 & & & & 1 & \\
\hline Total & $\mathbf{9 3 8}$ & $\mathbf{1 4 6}$ & $\mathbf{2 0}$ & $\mathbf{1 3}$ & $\mathbf{2}$ & $\mathbf{6}$ & $\mathbf{2}$ & $\mathbf{3}$ & $\mathbf{2}$ & $\mathbf{1}$ & $\mathbf{9 7}$ \\
\hline
\end{tabular}


Table 3: Correlation between HPV infection and some environmental risk factors

\begin{tabular}{|c|c|c|c|c|c|c|}
\hline \multicolumn{2}{|l|}{ Factor } & \begin{tabular}{|l}
$\mathrm{N}$ \\
90
\end{tabular} & $\begin{array}{l}\text { HPV positive cases } \\
12\end{array}$ & \begin{tabular}{|l|} 
Percentage \\
13.33
\end{tabular} & \multirow{2}{*}{$\begin{array}{l}\text { OR }(95 \% \mathrm{CI}) \\
1.23(0.65-2.33)\end{array}$} & \multirow{2}{*}{$\begin{array}{l}p \\
0.6443\end{array}$} \\
\hline & $\geq 30$ years & 848 & 134 & 15.80 & & \\
\hline \multirow{2}{*}{ Family income } & $\geq 240 \$$ & 680 & 114 & 16.76 & \multirow{2}{*}{$1.18(0.77-1.81)$} & \multirow{2}{*}{0.1226} \\
\hline & $<240 \$$ & 258 & 32 & 12.40 & & \\
\hline \multirow{2}{*}{ Sexual partner } & Single & 912 & 141 & 15.39 & \multirow{2}{*}{$1.05(0.35-3.13)$} & \multirow{2}{*}{0.7959} \\
\hline & Multiple & 26 & 5 & 19.23 & & \\
\hline \multirow{2}{*}{ Abortion } & No & 636 & 94 & 14.78 & \multirow{2}{*}{$1.23(0.91-1.69)$} & \multirow{2}{*}{0.3861} \\
\hline & Yes & 302 & 52 & 17.22 & & \\
\hline \multirow{2}{*}{ IUD } & No & 758 & 112 & 14.78 & \multirow{2}{*}{$0.91(0.75-1.09)$} & \multirow{2}{*}{0.2103} \\
\hline & Yes & 180 & 34 & 18.89 & & \\
\hline
\end{tabular}

OC: Oral contraceptive; IUD: Intra-uterine device; \$: US dollar; OR: Odds Ratio; CI: confidence intervals

\section{Discussion}

Cervical cancer is the most common malignancy among females in developing countries, with the highest prevalence in Latin America, Asia and Africa [20]. In Morocco, cervical cancer is the second most frequent female cancer after breast cancer and represents a major public health problem. The diagnosis is usually made in advanced stages, and mortality is high.

HPV plays a central role in the pathogenesis of cervical cancer and this viral infection is considered to be a necessary, though not always sufficient, cause. The development of human cervical cancer without the involvement of a specific HPV is exceptional.

Recently, prophylactics and therapeutic vaccination has shown promising results for preventing HPV infection as well as for the development of cervical neoplasia. However, development of effective vaccines would require a comprehensive study of the HPV genotypes in different regions of the world [21].

In this study, the prevalence of HPV DNA by PCR with the MY09/MY11 primers was $15.9 \%$ and is in concordance with the overall world distribution of HPV in asymptomatic women. A global epidemiologic study conducted by the International Agency for Research on Cancer showed that HPV prevalence is very different between countries. Lower prevalence was found in Europe (10.5\%)\ and intermediate prevalence was found in South America $(14.3 \%)$, whereas the highest prevalence was found in Africa (25.6\%) [22]. Moreover, similar results were found in other countries such as India (18.8\%) [23], Venezuela (15.6\%) [24] and Algeria (12.5\%) [25].

In the present study, the use of the hybridization method showed that HPV 16 and 18 are the most predominant genotypes in $13.71 \%$ and $8.87 \%$ respectively of HPV-positive cases. Worldwide, HPV 16 and 18 are the major genotypes found in cervical specimens and are mainly associated with the development of cervical lesions and cancer.

This study focused on HPV 16, 18, 31, 33, 35 and 45. In fact, Munoz et al. [7] have shown that theses types are the most frequent genotypes associated with the development of cervical precancerous lesions and cancer. Thus the hybridization method showed that HPV 16 was the predominant infectious type with $15.75 \%$ of HPVDNA positive simples. Worldwide, HPV 16 is the most common type followed by HPV 18 [8,21].

Interestingly, in the present study, multiple HPV infections were observed in only $2 \%(3 / 146)$ of the HPV-positive specimens. A previous study on Moroccan cervical cancer specimens found multiple infections in $35.4 \%$ of specimens [26]. Co-infection with multiple HPV types is a common finding of 
many molecular epidemiologic studies of cervical cancer. Some HPV types might interact or act synergistically to induce lesion development or progression [27]. Indeed, the risk of high-grade lesions and of invasive cervical cancer seems to be considerably increased among women with multipletype infections compared with those harbouring a single HPV type [28]. Herrero et al. (2005) have shown that the risk of cervical lesions strongly increases when HPV 16 and other types are not present alone [29]. Moreover, Fife et al. (2001) suggested that some HPV types might cooperate with HPV 16 to produce dysplasia or cancer [30]. This finding provides evidence that women with multiple infections must be closely monitored to prevent evolution to cervical cancer.

Among the 146 HPV-positive cases, 97 were untyped. These HPVs could correspond to other high-risk HPVs or belong to low-risk HPVs that are usually related to benign lesions.

It is widely accepted that in addition to HPV infection, other cofactors could have a great role in the development of cervical lesions. These factors may be classified into two groups: 1 . environmental or exogenous cofactors, including the use of oral contraceptives (OCs), tobacco smoking, diet, cervical trauma, and co-infection with human immunodeficiency virus (HIV) and other sexually transmitted agents; 2. host cofactors, including endogenous hormones, genetic factors such as human leukocyte antigen, and other host factors related to the host's immune response [31]. In the current study, due to limited data, only risk factors related to age, socio-economic level, sexual activity, oral contraception, and family situation were examined.

All the women harbouring HR HPV were more than 30 years old. In this group, $80 \%$ were aged between 45 and 55 years. There is evidence that this age group is more exposed to persistent HR HPV. Previous studies have shown that the peak prevalence of invasive cancer occurs at approximately 40-50 years old [7]. Considering the normal and abnormal cytology results, the overall prevalence of HPV was not statistically significant. However, a similar study conducted by Ghaffari et al. [21] had shown that HPV infection was significantly associated with cervical lesions in asymptomatic women. This observation could be related to the study populations. Indeed, the results of the current study showed a low frequency of ASC-US/ASC-H, L-SIL and H-SIL based on cytology.
In this study, the only statistically significant association was found between HPV infection and oral contraceptive use. However, no statistically significant association between HPV infection and the other risk factors after adjustment for age group, parity, family income, number of sexual partners, abortion episodes and use of intrauterine device were found by either unvaried and multivariate logistic regression models. Worldwide, different studies have shown that these risk factors are closely related to the development of cervical lesions and cancer $[31,32,33,34]$. Thus, environmental and endogenous cofactors will not influence HPV infection but could be implicated in the lesion progression and cancer development.

According to the findings in the current study, high rates of infection with HPV genotypes in sexually active Moroccan women make molecular investigation for HPV16, 18 and 31 essential in clinical approach. However, HPV 33, 35 and 45 are less frequent in this population.

In Morocco, the diagnosis of cervical lesions rests exclusively on the cytology-based screening that offers substantial protection, although current coverage is low. The introduction of HPV DNA testing in cervical cancer management will greatly benefit early stage HPV detection and help prevent development of cervical lesions and cancer. This may offer a significant opportunity for the Moroccan National Program against cervical cancer to control this devastating disease and save many lives.

\section{Acknowledgments}

This study has been kindly supported by grants from the CRECET: Research Centre in Clinical Epidemiology and Therapeutic Trials, Faculty of Medicine and Pharmacy, Mohammed V Souissi University, Rabat, Morocco. The authors are very grateful to Pamela Pattie for her assistance in editing and all the staff of the gynaecology and anatomy pathology departments of Ibn Sina Hospital.

\section{References}

1. Roberts CC, Tadesse AS, Sands J, Halvorsen T, Schofield TL, Dalen A, Skjeldestad FE, Jansen KU (2006) Detection of HPV in Norwegian cervical biopsy specimens with typespecific PCR and reverse line blot assays. J Clin Virol 36: 277-82.

2. Amrani M, Lalaoui K, El Mzibri M, Lazo P and Belabbas MA (2003) Molecular detection of human papillomavirus in 594 uterine cervix samples from Moroccan women (147 biopsies and 447 swabs). J Clin Virol 27: 286-95.

3. IARC. International Agency on Research on Cancer (1995) Monograph on cancer, Human papillomavirus. Vol : 64. World Health Organization. 
4. Zur Hausen H (2000) Papillomaviruses causing cancer: evasion from host-cell control in early events in carcinogenesis. J Natl Cancer Inst 92: 690-98.

5. Woodman CB, Collins SI, Young LS (2007) The natural history of cervical HPV infection: unresolved issues. Nat Rev Cancer 7: 11-22.

6. Wei YC, Chou YS, Chu TY (2007) Detection and typing of minimal human papillomavirus DNA in plasma. Int $\mathbf{J}$ Gynaecol Obstet 96: 112-16.

7. Muñoz N, Bosch FX, De Sanjosé S, Herrero R, Castellsagué X, Shah KV Snijders PJF and Meijer CJLM (2003) Epidemiologic classification of human papillomavirus types associated with cervical cancer. N Engl J Med 348: 518-27.

8. Kay P, Soeters R, Nevin J, Denny L, Dehaeck CMC, Williamson AL (2003) High prevalence of HPV 16 in South African women with cancer of the cervix and cervical intraepithelial neoplasia. J Med Virol 71: 265-73.

9. Andersson S, Mints M, Sällström J, Wilander E (2005) The relative distribution of oncogenic types of human papillomavirus in benign, pre-malignant and malignant cervical biopsies. A study with human papillomavirus deoxyribonucleic acid sequence analysis. Cancer Detect Prev 29: 37-41.

10. Brestovac B, Harnett GB, Smith DW, Shellam GR, Frost FA. (2005) Human papillomavirus genotypes and their association with cervical neoplasia in a cohort of Western Australian women. J Med Virol 76: 106-10.

11. Lazo PA (1999) The molecular genetics of cervical carcinoma. Br J Cancer 80: 2008-18.

12. Cuzick J, Clavel C, Petry KU, Meijer CJLM, Hoyer H, Ratnam S ,Szarewski A, Birembaut P, Kulasingam S, Sasieni P and Iftner T (2006) Overview of the European and North American studies on HPV testing in primary cervical cancer screening. Int J Cancer 119: 1095-101.

13. Cox T and Suzick J (2006) HPV DNA testing in cervical cancer screening: From evidence to policies. Gynaecologic Oncology 103: 8-11.

14. Cuzick J, Szarewski A, Cubie H, Hulman G, Kitchener H, Luesley D, McGoogan E, Menon U, Terry G, Edwards R, Brooks C, Desai M, Gie C, Ho L, Jacobs I, Pickles C, Sasieni P (2003) Management of women who test positive for high-risk types of human papillomavirus: the HART study. Lancet 362: 1871-76.

15 A.N.A.E.S (1999) Conduite à tenir devant un frottis cervicoutérin anormal. Ann Pathol 19: 57-75.

16. Smith JHF (2002) Review Bethesda 2001. Cytopathology 13: 4-10.

17. Sambrook J, Fritsch EF, Maniatis T (1989) Molecular Cloning: A laboratory manual. Cold Spring Harbor: Cold Spring Harbor Laboratory Press 1659 p.

18. Husnjak K, Grce M, Magdić L, Pavelić K (2000) Comparison of five different polymerase chain reaction methods for detection of human papillomavirus in cervical cell specimens. J Virol Methods 88: 125-34.

19. Bauer HM, Ting Y, Greer CE, Chambers JC, Tashiro JC, Chimera CL, Reingold A and Manos M (1991) Genital human papillomavirus infection in female university students as determined by a PCR-based method. JAMA 256: 472-77.

20. Parkin DM, Pisani P, Ferlay J (1999) Estimates of the worldwide incidence of 25 major cancers in 1990. Int J Cancer 80: 827-41.
21. Ghaffari SR, Sabokbar T, Mollahajian H, Dastan J, Ramezanzadeh F Ensani F, Yarandi F, Mousavi-Jarrahi A, Mohagheghi MA, Moradi A (2006) Prevalence of Human Papillomavirus Genotype in Women with Normal and Abnormal Cervical Cytology in Iran. Asian Pacific J Cancer Prev 7: 529-32.

22. Clifford GM, Gallus S, Herrero R, Muñoz N, Snijders PJ, Vaccarella S, Anh PT, Ferreccio C, Hieu NT, Matos E, Molano M, Rajkumar R, Ronco G, de Sanjosé S, Shin HR, Sukvirach S, Thomas JO, Tunsakul S, Meijer CJ and Franceschi S (2005) Worldwide distribution of human papillomavirus types in cytologically normal women in the International Agency for Research on Cancer HPV prevalence surveys: a pooled analysis. Lancet 366: 991-98.

23. Kumar K, Venkateswaran K, Neerja B, Alka K, Kusum V (2007) Comparative evaluation of smear cytology \& hybrid capture II for the diagnosis of cervical cancer.Indian. J Med Res 126: 39-44.

24. Núñez-Troconis J, Delgado M, González J, Mindiola R, Velásquez J, Conde B, Whitby D, Munroe DJ (2009) Prevalence and risk factors of human papillomavirus infection in asymptomatic women in a Venezuelan urban area. Invest Clin 50: 203-12

25. Hammouda D, Muñoz N, Herrero R (2005) Cervical Carcinoma in Algiers, Algeria: Human Papillomavirus and Lifestyle Risk Factors. Int J Cancer 113: 483-89.

26. Meftah El Khair M, El Mzibri M, Ait Mhand R, Benider A, Benchekroun N, El Fahime M, Benchekroun MN and Ennaji MM (2009) Molecular detection and genotyping of human papillomavirus in cervical carcinoma biopsies in an area of high incidence of cancer from Moroccan women. J Med Virol 81: 678-84.

27. Trottier H, Mahmud S, Costa MC, Sobrinho JP, Franco ED, Rohan TE, Ferenczy A, Villa LL and Franco EL (2006) Human Papillomavirus Infections with Multiple Types and Risk of Cervical Neoplasia. Cancer Epidemiol Biomarkers Prev 15: 1274-79.

28. Van Der Graaf Y, Molijn A, Doornewaard H, Quint W, van Doorn LJ and Van Den Tweel J (2002) Human papillomavirus and the long-term risk of cervical neoplasia. Am J Epidemiol 156: 158-64.

29. Herrero R, Castle PE, Schiffman M, Bratti MC, Hildesheim A, Morales J, Alfaro M, Sherman ME, Wacholder S, Chen S, Rodriguez AC and Burk RD (2005) Epidemiologic profile of type specific human papillomavirus infection and cervical neoplasia in Guanacaste, Costa Rica. J Infect Dis 191: 1796- 807

30. Fife KH, Cramer HM, Schroeder JM and Brown DR (2001) Detection of multiple human papillomavirus types in the lower genital tract correlates with cervical dysplasia. J Med Virol 64: 550-59.

31. Castellsague X and Muñoz N (2003) Cofactors in human papillomavirus carcinogenesis-role of parity, oral contraceptives, and tobacco smoking. J Natl Cancer Inst Monogr 31: 20-28.

32. Franceschi S, Rajkumar T, Vaccarella S, Gajalakshmi V, Sharmila A, Snijders PJ, Muñoz N, Meijer CJ and Herrero R (2003) Human papillomavirus and risk factors for cervical cancer in Chennai, India: A case-control study. Int J Cancer 107: 127-33.

33. Murthy NS and Matthew A (2002) Risk factors for precancerous lesions of the cervix. Eur J Cancer Prev 9: 514. 
34. Tay SK and Tay KJ (2004) Passive cigarette smoking is a risk factor in cervical neoplasia. Gynecol Oncol 93: 116-20.

\section{Corresponding author:}

Dr. Zaïtouna Alhamany

Département d'Anatomie Pathologique

Maternité Souissi. CHU Ibn Sina

BP 6543 Rabat Instituts

10001 Rabat, Maroc

Phone: (+212) 662.36.39.19

Fax : (+212) 537.67.02.24

E-mail: alhamany.z@gmail.com

Conflict of interests: No conflict of interests is declared. 